Results Cognitive group therapy based on schema focused approach decreased maladaptive schemas in the experimental group compare to the control group. Subsequently depression was decreased in the experimental group compare to the control group.

Conclusion This study showed that Schema Therapy is an effective treatment for depression in special populations. Life of people living with HIV, particularly in prisons, is full of emotional deprivation, defects and damage; these reasons can cause conditions which is lead to depression. ST through modulation maladaptive schemes could reduce depression in prisoners living with HIV.

\section{P4.41 EFFECT OF HIV RELATED STIGMA ON UTILISATION OF SKILLED BIRTH ATTENDANTS BY HIV POSITIVE WOMEN IN NIGERIA; A SYSTEMATIC REVIEW}

Foluso Ishola. Japan International Cooperation Agency, Lagos, Nigeria

\subsection{6/sextrans-2017-053264.538}

Introduction HIV/AIDS-related stigma is recognised as a major barrier to utilisation of health facilities for delivery by pregnant women living with HIV/AIDs and an impediment to prevention of mother to child (PMTCT) of HIV. Greater comprehension of contextual factors that specifically reduce HIV-positive women's access to maternity care is essential. This paper reviews the existing research literature on AIDS stigma experienced by HIV positive pregnant women in Nigeria with the objective of documenting the current status of research, highlighting major findings and identifying key gaps remaining.

Methods Fifteen publications were identified after a structured search of six electronic databases for published literature between 2000 and 2016 that potentially contained data on HIV-related stigma, utilisation of skilled birth attendants and delivery outcomes. We used the method of meta-synthesis to summarise the findings from the qualitative studies.

Results Stigmatisation experienced includes exclusion from maternity services,termination of appointment, abuse, disrespect, maltreatment, negative attitudes and hostility amongst others. There is increasing concern about health care workers reluctance to care for and treat HIV positive pregnant women. This is further exacerbated by weak health systems and poor legal and ethical framework. HIV positive pregnant women are reluctant to deliver their babies in a health facility with a skilled attendant due to the risk being labelled HIV positive. This avoidance could contribute to obstetric complications and avoidable maternal deaths.

Conclusion Interventions should be introduced to reduce HIVrelated stigma. Training health workers on the elements of psychosocial care and avoiding stigmatising behaviour is important. Research exploring linkages between HIV related stigma and maternity services uptake are largely missing and need to be prioritised. In addition, more research is needed to advance conceptual understanding of stigma within the cultural context of Nigeria.
P4.42 KAP STUDY AND PREVALENCE OF HIV AND SYPHILIS IN HONDURA'S PRIVATE FREEDOM PERSONS

Freddy Tinajeros. Independent Consultant, La Paz, Bolivia

\subsection{6/sextrans-2017-053264.539}

Introduction According to the STI/HIV/AIDS Department's has recorded a total of 32573 cases Accumulated of which 22737 are cases of Advanced Infection and 9836 are asymptomatic HIV. The only previous study of persons deprived of liberty (PPL) was in 1999, which included three cities in Honduras and 2095 people were recruited, the majority of which were men. The prevalence of syphilis was $1.8 \%$.

Methods A cross-sectional study, which used systematic random sampling by clusters, each penal centre gave a proportional share of its population. The universe of persons deprived of liberty consisted of 5813 men (3,531 TGUs and 2,282 SPS) and 430 women (346 TGUs and 84 SPS), who make a total of 6159 . The protocol was approved by the Biomedical Research Committee of the National Autonomous University of Honduras (CEIB).

Results Regarding HIV sero-prevalence, 1.9\% (95\% CI, $0.8-$ 4.2) of HIV-infected men compared to $0.6 \%$ (CI 95\%, 0.0 3.4) of women, however, men Of SPS 2 in 3.3\% (IC 95\%, 0.9-8.2) of HIV compared to $1.0 \%(95 \% \mathrm{CI}, 0.1-3.5)$ in TGU men, whereas TGU 2 women were $0.8 \%$ (95\% CI, 0.0 4.5 ) and women of SPS $0.0 \%$ (95\% CI, 0.0-8.8), ie no cases were found in the study sample, however this does not mean that there is no HIV in them. The incidence of syphilis (using as a criterion RPR posi2vo confirmed by TPPA) was $1.5 \%$ (95\% CI, 0.3-4.3) in TGU men compared to 3.3\% (95\% CI, $0.9-8.2)$ in SPS men, While in TGU women it was $0.8 \%$ (95\% CI, 0.0-4.5) compared to 7.5\% (CI 95\%, 1.6-20.4) of SPS women.

Conclusion HIV prevalence is higher in San Pedro Sula than in Tegucigalpa, as is the incidence of syphilis, but the highest of all is the prevalence of cumulative syphilis, which implies that there is unprotected sex and high risk. Also, while most know where to perform the HIV test only half were performed and the syphilis test less than a third. One-third of men and women suffered from discrimination and PPL discrimination, with verbal attacks (threats, scoldings, humiliations) among the $2 \mathrm{p}$ of attacks, and less than one-twentieth reported this discrimination.

\section{P4.43 SOCIO-ECONOMIC STATUS OF MEN ENGAGING IN AGE DISPARATE SEX: A SECONDARY ANALYSIS OF NATIONALLY REPRESENTATIVE DATA IN SOUTH AFRICA}

${ }^{1}$ Gavin George, 'Sean Beckett, ${ }^{2}$ Brendan Maughan-Brown, ${ }^{3}$ Meredith Evans. ${ }^{1}$ Health Economics and HIVIAIDS Research Division, University of Kwazulu-Nata, Durban, South African Republic; ${ }^{2}$ Southern Africa Labour And Development Research Unit (SALDRU), Department of Economics, University, Cape Town, South African Republic; ${ }^{3}$ Department of Anthropology, York University, Toronto, Canada

\subsection{6/sextrans-2017-053264.540}

Introduction Studies have highlighted the increased risk in contracting HIV for young women who engage in age disparate sexual partnerships. However, there is a dearth of evidence about the socioeconomic profile of men who engage in these types of sexual partnerships. This study focuses on men who engage in age disparate sex and specifically whether there are socioeconomic-status (SES) asymmetries between those 
who engage in age disparate sex compared to those who do not engage in age disparate sex.

Methods The data for this study comes from the third National HIV communication Survey (NCS) of South Africa conducted in 2012. The sample consists of 4065 randomly selected men between the ages of 16 and 55 years. Respondents were interviewed by means of a structured questionnaire. Men were classified according to the types of sexual partnerships they had engaged in during the previous 12 months. Multiple logistic regression models were used to assess the association between SES and sexual partnership type, controlling for potential confounders.

Results Sixty percent of men had been involved in only age similar partnerships, $31 \%$ in at least one age disparate partnership (partner is 5 to 9 years younger) and $10 \%$ in relationships where the female partner is 9 years or more years younger. The results indicate that household wealth is not significantly related to the likelihood of men engaging in age disparate sex or intergenerational sex. Interestingly, experiencing deprivation in informal urban areas increases men's likelihood of engaging in age disparate sex (AOR: 1.3, p<0.05).

Conclusion The results reveal that it is poorer men in informal urban settlements who are engaging in age disparate sex. Literature suggests that young women primarily engage in transactional sex with older men to support their basic needs. However, these data do not support this hypothesis and future research must identify the full range of factors fueling age disparate relationships.

\section{P4.44 PRIMARY HEALTHCARE WORKERS' PERCEPTIONS REGARDING CALLING SEXUAL PARTNERS OF PREGNANT WOMEN WITH SYPHILIS FOR TREATMENT}

Geraldo Bezerra da Silva Junior, Ana Fátima Braga Rocha, Kairle Santana Romualdo, Priscila de Sousa Xavier, Maria Alix Leite Araújo. University of Fortaleza, Fortaleza - CE, Brazil

\subsection{6/sextrans-2017-053264.541}

Introduction Due to low treatment coverage of sexual partners of pregnant women with syphilis in Brazil, this study aims to investigate the perceptions of primary healthcare workers about the calling of these partners for treatment.

Methods This is a descriptive study with qualitative designs conducted in six primary healthcare facilities including those with the highest numbers of pregnant women with syphilis in the city of Fortaleza, Ceará, Brazil. A total of 20 healthcare workers were included (seven physicians and thirteen nurses) and six healthcare unit's coordinators. The study was performed from June to September 2016 through semi-structured interviews, and content analysis was done.

Results According to interviewed healthcare workers, the calling and treatment of sexual partners of pregnant women with syphilis are complex and challenges activities, especially when they are not from the healthcare unit area or are illicit drug users. They pointed chauvinism as one of the main barriers and gender issues that causes resistance to go to the healthcare units for treatment. Lack of symptoms also makes partners believe they have no infection. There are also marital problems caused by the infection's diagnosis. The healthcare workers said not to feel able to these types of demands and require training. They believe that higher disclosures in different medias about syphilis and its consequences and "men prenatal care" would be important strategies to improve syphilis treatment coverage.

Conclusion Physicians and nurses in the primary care, as well as health units' coordinators, have several difficulties for calling and treating sexual partners of pregnant women with syphilis and do not feel able enough to face this problem.

\section{P4.45 INDIVIDUAL AND PARTNERSHIP FACTORS ASSOCIATED WITH ANTICIPATED VERSUS ACTUAL PARTNER NOTIFICATION FOLLOWING STI DIAGNOSIS AMONG MEN WHO HAVE SEX WITH MEN AND/OR WITH TRANSGENDER WOMEN IN LIMA, PERU}

${ }^{1}$ Hannan M Braun, ${ }^{2}$ Eddy R Segura, ${ }^{3}$ Javier R Lama, Jordan E Lake, ${ }^{3}$ Jessica Rios, ${ }^{3}$ Manuel V Villaran, ${ }^{3}$ Jorge Sanchez, ${ }^{5}$ Jesse L Clark. ${ }^{1}$ Doris Duke International Clinical Research Fellowship, UCLA Saphir Program, UCSF School of Medicine, San Francisco, CA, USA; ${ }^{2}$ UCLA Geffen School of Medicine, Lima - Peru; ${ }^{3}$ Asociacion Civil Impacta Salud y Educacion, Lima - Peru; ${ }^{4}$ McGovern Medical School at UThealth, Department of Internal Medicine, Division of Infectious Disease, Houston, TX, USA; ${ }^{5}$ UCLA Geffen School of Medicine, Department of Medicine, Division of Infectious Diseases, Los Angeles, CA, USA

\subsection{6/sextrans-2017-053264.542}

Introduction A detailed understanding of partner notification (PN) practices following STI diagnosis can improve PN strategies. Using data from 2 PN intervention trials in Lima, Peru, we assessed participant- and partner-level factors guiding partner-specific STI notification behaviour, including discordances between anticipated and actual notification.

Methods From 2012-14, newly STI-diagnosed (gonorrhoea, chlamydia, syphilis) men who have sex with men (MSM) and/ or with transgender women in Lima reported recent partners' characteristics, anticipated PN practices, and actual PN outcomes 14 day following STI diagnosis. In this sub-analysis of control-arm participants, GEE Poisson regression analyses assessed factors guiding PN outcomes.

Results Participants $(\mathrm{n}=150)$ predominantly identified as homosexual (70\%) and moderno (versatile sexual role, 55\%); $55 \%$ of partners $(n=402)$ were casual. $35 \%$ of partners were notified overall, though only $51 \%$ of anticipated PN occurred and $26 \%$ of notifications were unanticipated. $47 \%$ of participants did not notify any partners, while $24 \%$ notified all partners. PN was more frequent for main vs. casual (adjusted prevalence ratio $[\mathrm{aPR}] 0.55, \mathrm{p}<0.01$; adjusted for anticipated $\mathrm{PN})$ or commercial (aPR $0.29, \mathrm{p}<0.05)$ partners, with a trend toward notifying partners that used condoms (crude PR 1.30, $\mathrm{p}=0.09$ ). PN frequency did not differ by STI diagnosis. Anticipated PN predicted actual PN (aPR 1.60, p<0.01) imperfectly as $81(54 \%)$ participants' PN practices did not match anticipated behaviour. Successful notification despite anticipated silence (40 participants, 63 partners) was associated with stable partnerships and perceived community norms supporting PN. Failure of PN despite intent (43 participants, 73 partners) more frequently occurred when oral sex with the partner was exclusively reported, with a trend towards identifying the partner as activo (insertive role).

Conclusion Anticipated PN imperfectly reflects actual PN behaviour. Future interventions to improve notification should acknowledge the differing partnership contexts maintained by MSM. 